\title{
The Northern Flying Squirrel
}

A PHOTOGRAPHIC STUDY

by H. S. Dommasch, Saskatoon

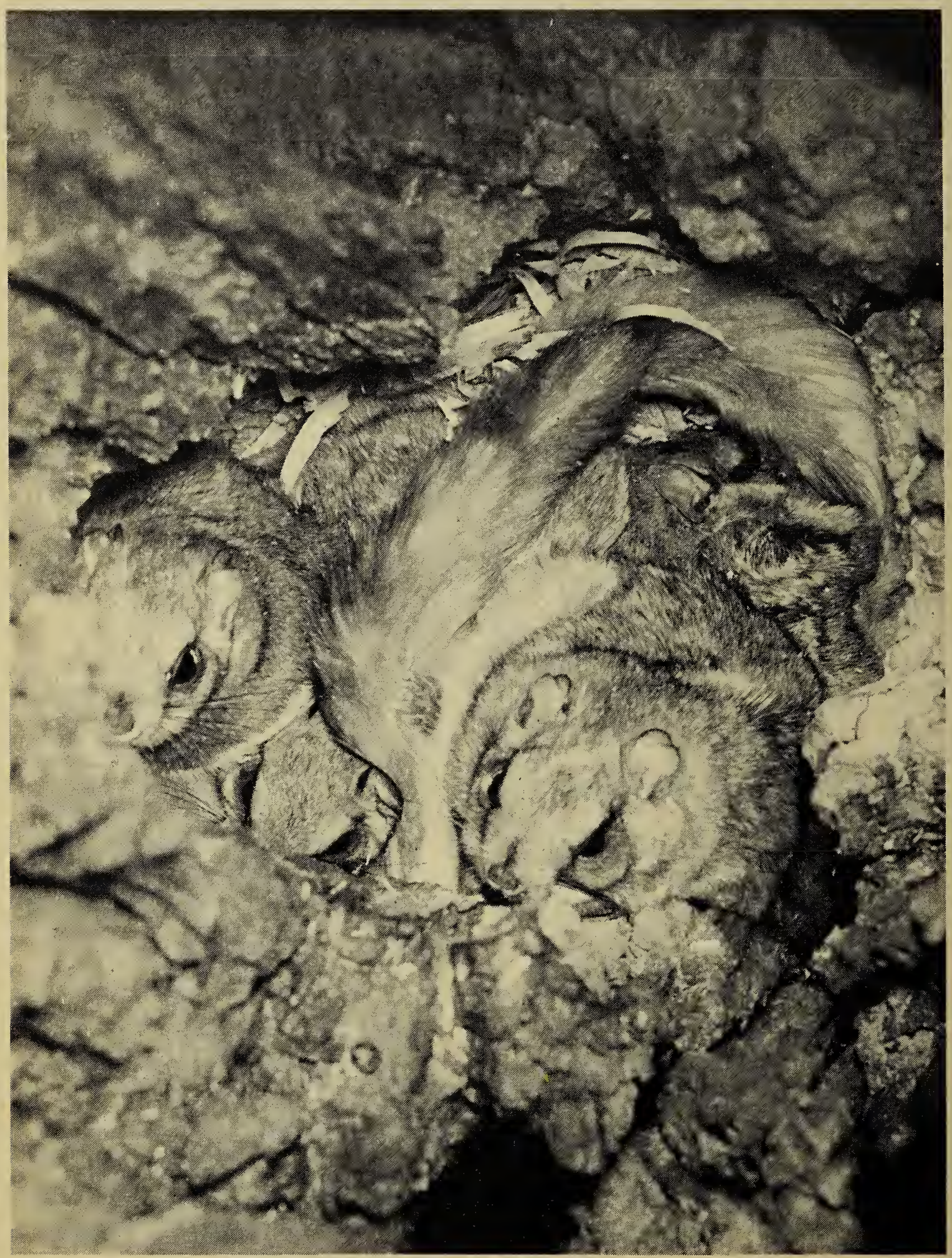

Northern Flying Squirrels do hibernate but they often congregate together for warmth during the winter months. As many as twelve have been seen roosting together in old snags. 


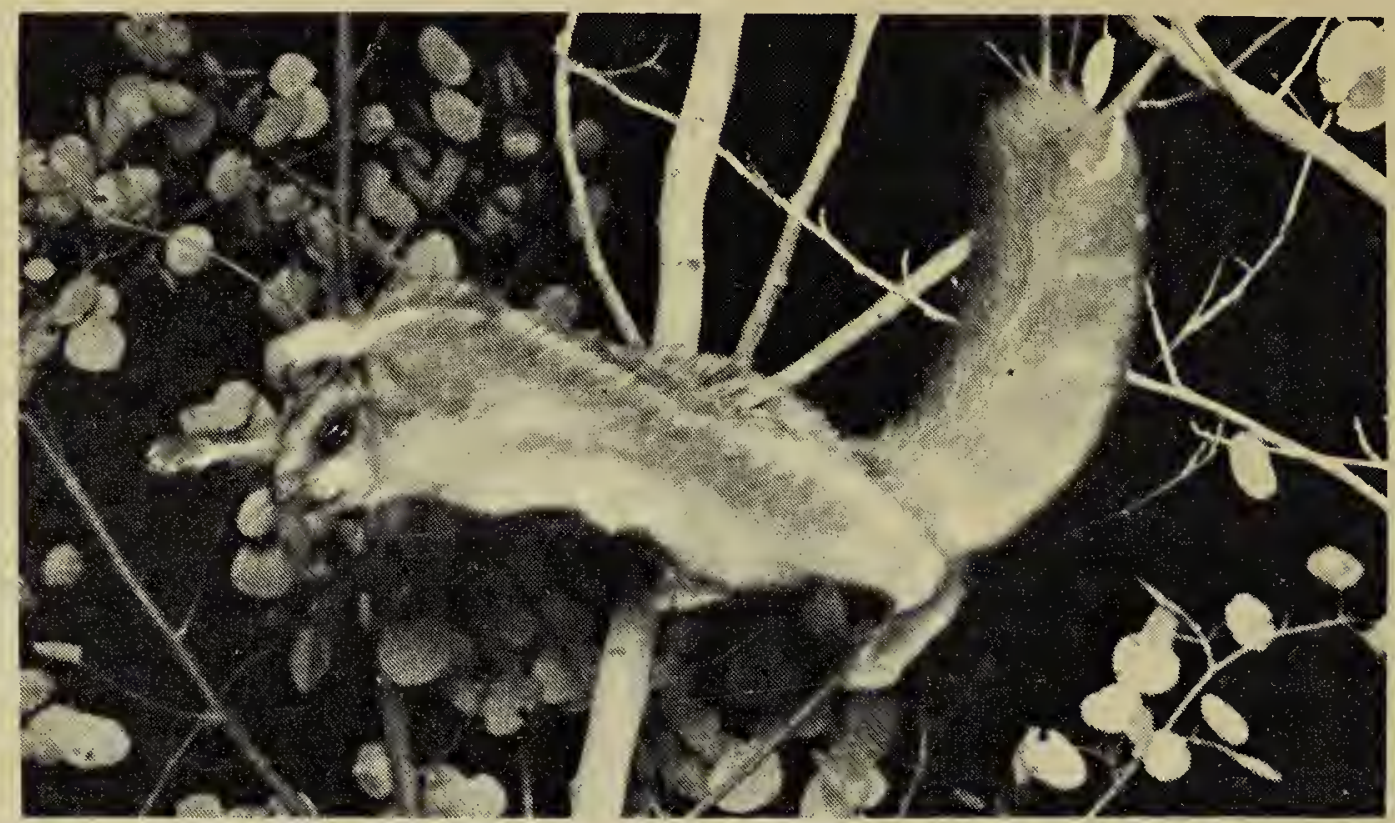

The Northern Flying Squirrel can glide about 150 feet or more. (Note the position of the head.)

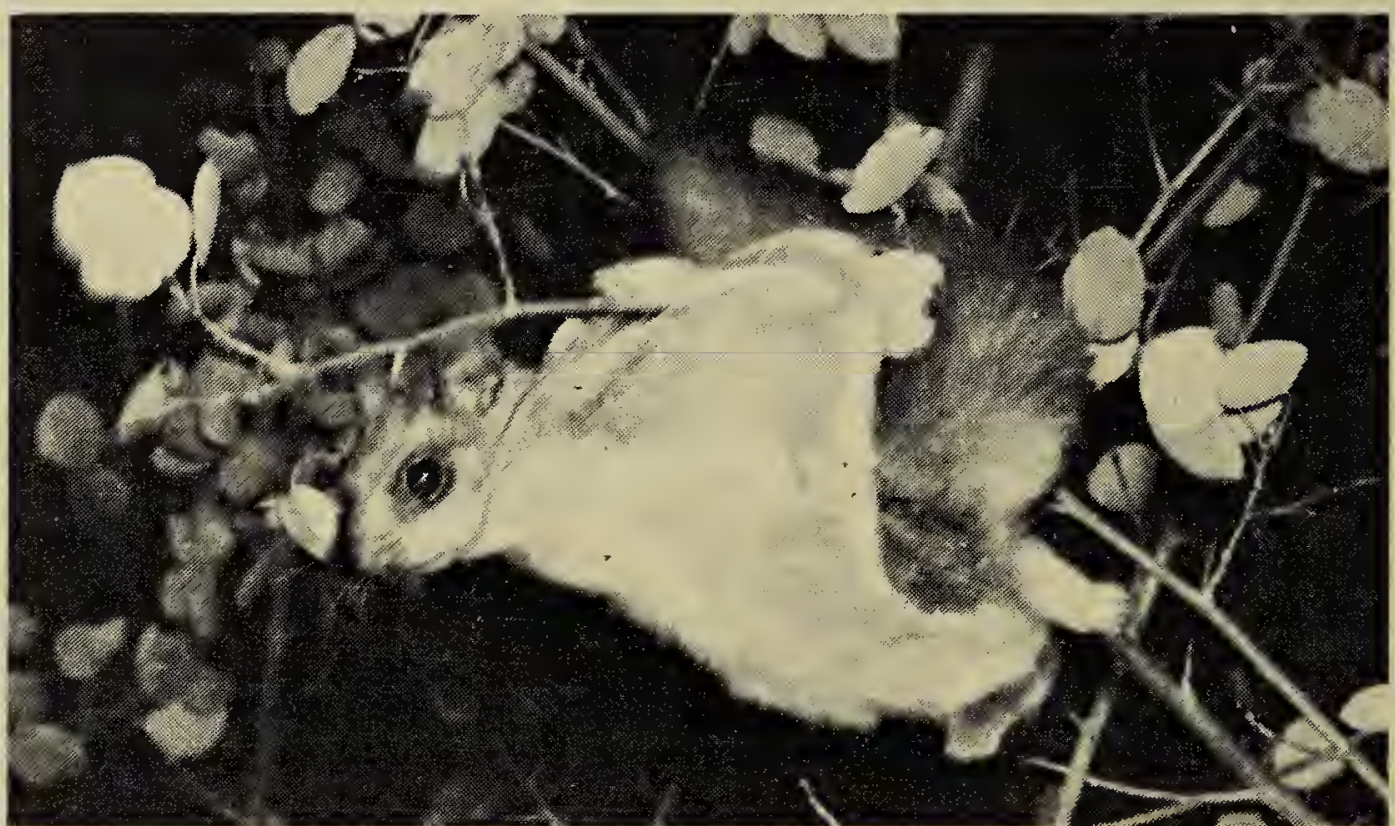

The loose furry membrane is further extended by cartilages from the fore limbs.

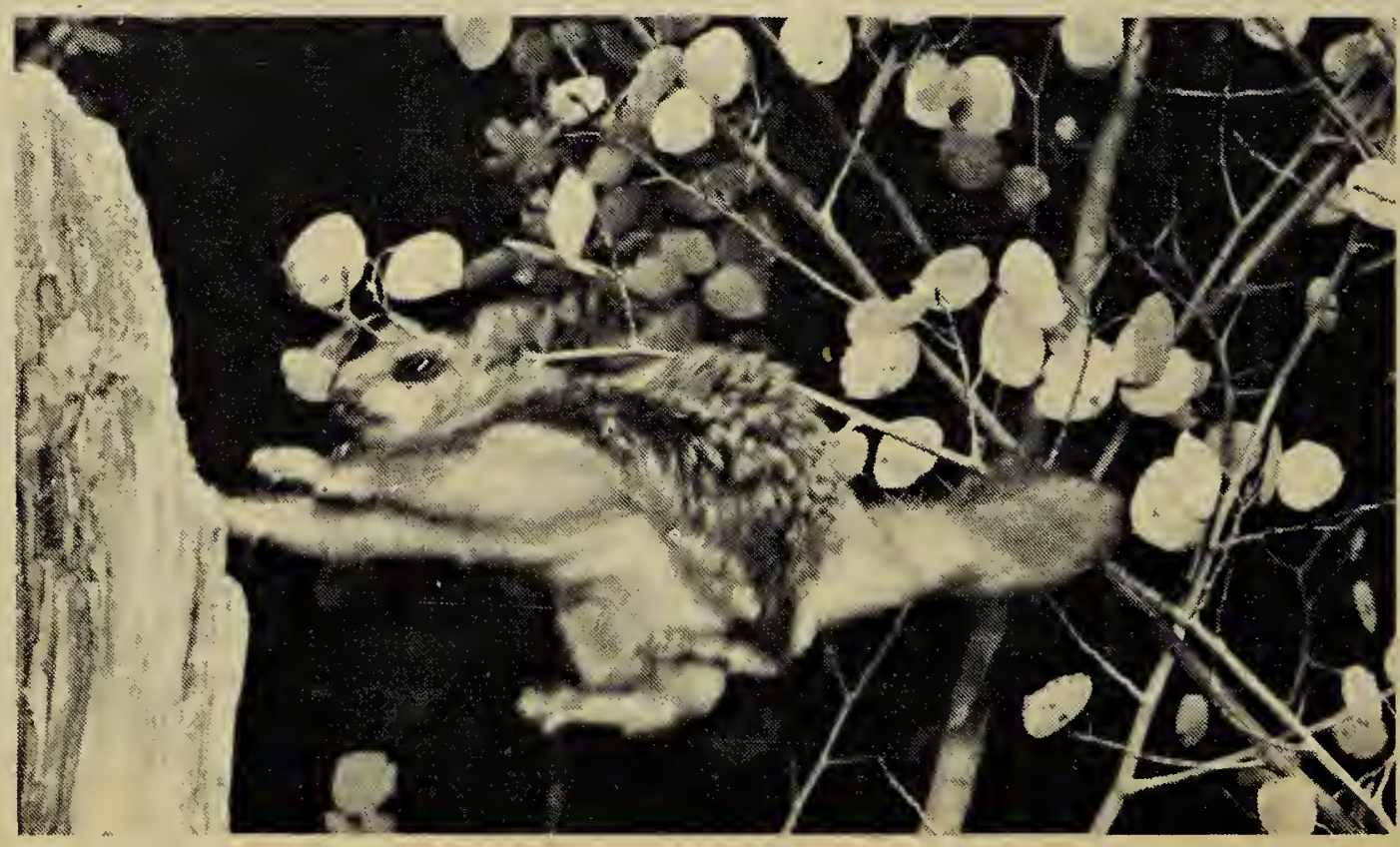

Before landing the squirrel checks its speed by manipulating its tail and it comes to rest head up on the trunk of a tree. 
